International Journal of Applied Economics, Finance and Accounting

ISSN 2577-767X

Vol. 8, No. 1, pp. 38-45.

2020

DOI: $10.33094 / 8.2017 .2020 .81 .38 .45$

(C) 2020 by the authors; licensee Online Academic Press, USA

\title{
Revisiting the Demand for Money in Saudi Arabia
}

Moayad H. Al Rasasi ${ }^{*}$

John H. Qualls ${ }^{2}$

\section{Economic Research Department Saudi Arabian Monetary Authority, Riyadh, Saudi Arabia. \\ EEmail:moalrasasi@gmail.com \\ Licensed: \\ This work is licensed under a Creative \\ Commons Attribution 4.0 License.}

Keywords:

Money demand

Cointegration

Hijra data

Gregorian dato

ECM

JEL Classification

C13; C22; E41; E52; F41.

Received: 21 September 2020

Revised: 6 October 2020

Accepted: 23 October 2020

Published: 10 November 2020

(* Corresponding Author)

\begin{abstract}
This paper revisits the issue of the demand for money (in this case, M3) in the Kingdom of Saudi Arabia. Well-known standard analytical techniques were employed, including tests of the data for unit roots, cointegration relationships, and the use of error correction modeling to estimate income elasticities and the impact of interest rates on money demand. However, this paper differs from most in its attention to the data used in the analysis, specifically, the data for Ms, which is the dependent variable. Two separate (but related) issues were addressed - the traditional way of measuring the money supply and its impact on the models using it, and the fact that monthly and annual money supply data prior to mid-1988 are still published using the Hijra fiscal year, since monetary statistics were not kept on a Gregorian basis. The problems that these issues cause are examined and revised M3 data series are tested. Addressing both of these problems is done by converting the Hijra-based data into a Gregorian basis and using the monthly average of Ms for the annual series, rather than the end of year data traditionally used. The use of the new series appears to result in better-fitting and more stable models. This paper recommends that future statistical research, particularly using pre-1988 data, use the revised data in place of the currently published series.
\end{abstract}

Funding: This study received no specific financial support.

Competing Interests: The authors declare that they have no competing interests.

\section{Introduction}

The conduct of monetary policy is one of the most important and essential tasks that a country's Central Bank has. The management of the country's money supply is essential to the conduct of this policy. This task is particularly important to developed economies with floating currencies, whose livelihood depends on the competitiveness of their exports and their import-competing industries, and whose capital spending is influenced by the cost of capital, and both investment and personal consumption are directly affected by the level of interest rates. However, even in a resource-rich developing economy with a pegged currency, whose economy is less interest-sensitive, with businesses that are less leveraged and consumers who carry lighter debt loads, the management of the money supply is still of critical importance. Liquidity management, the control of inflation, and the safety and security of the nation's financial institutions all depend on the ability of the Central Bank to closely match the supply of and demand for money, in its various forms.

Economists put much effort in understanding the behavior of money demand; therefore, various theories (e.g., Quantity Theory, Keynesian Theory, Inventory Theory known as "The Baumol-Tobin Model", Friedman's Theory, and Cash-in-Advance Model) have attempted to lay out the key determinants of money demand. With all the theoretical foundations being developed, empirically there has been continuous research validating these theories; Banafea (2012) sheds light intensively on the empirical studies conducted on advanced and less advanced economies based on the materialized theories.

It is essential to emphasize that our motivation for this research arises from several sources. First is the issue of the traditional measurement of money supply, which uses the end-of-period convention. In other words, the money supply measurement for an entire year is based on a snapshot of various December 31 commercial and central bank balances. In sharp contrast, the other variables that enter into the determination of the money supply (the Consumer Price Index "CPI”, real Gross Domestic Product "GDP”, and the interest 
rate) all are based on averages (or totals, in the case of GDP) of monthly (or even weekly or daily) data. Therefore, our purpose is to examine if the use of monthly average money stock data would result in more robust relationships being estimated.

The next issue is the fact that the existing monthly money supply data prior to 1988 is based on the Hijra fiscal calendar, which consists of 12 Hijra months (based on the lunar calendar) and a 354-355 day year, versus the Gregorian calendar with a 365-366 day year. To further simplify matters, the Hijra fiscal year used for the published money supply data prior to mid-1988 began on the first day of the seventh Hijra month (Rajab I) and ended on the last day of the sixth month (Jumada II).

The combination of these two factors results in having inaccurate estimation results and this problem gets even worse the further back in time we go. As an example of the distortions that this causes, consider the following. In Saudi Arabian Monetary Authority's (SAMA) latest Annual Report database, the M3 figure for the Hijra fiscal year that allegedly corresponds to December 31, 1980 is actually the M3 value at the end of the Hijra fiscal year AH 1400/1401 (30 Jumada II, 1401), which corresponds to May 4, 1981, over four months later than December 31, 1980. In order to rectify this problem, SAMA's Research conducted by Qualls, Algahtani, and Al Sayaary (2017) developed a methodology to convert the pre-1988 Hijra data into its Gregorian equivalent. Although the converted data are estimates, they are much more precise than using the Hijra data as published. ${ }^{1}$ This paper will be the first that uses the new Gregorian money supply data for analytical econometric analysis of monetary aggregates. ${ }^{2}$

The rest of the paper is organized as follows: whilst section 2 describes the money demand theoretical framework, section 3 provides an overview of the empirical research with notable attention to research focusing on Saudi Arabia. The description of data is contained in section 4, while the econometric methodology and results are described in section 5. The conclusion is contained in section 6 .

\section{Theoretical Background}

Despite the presence of various theories (e.g., Quantity Theory, Keynesian Theory, Inventory Theory known as "The Baumol-Tobin Model", Friedman's Theory, and Cash-in-Advance Model), formulating the determinants of money demand, the mainstream of empirical studies assessing the behavior of money demand still relies on the Keynesian's theory in order to understand the relationship between money demand and its determinants. Consequently, this paper will rely on the Keynesian theory to assess the relationship among the demand for money and its determinants in Saudi Arabia.

Likewise, prior to proceeding with the empirical analysis, it is also important to understand the foundation of Keynesian theory. According to this theory, people demand money either for daily transactions, precautionary purposes, or speculative purposes, as a "store of wealth." Based on these motives, it can be inferred that the first and second motives for people to hold money are related proportionally to income, which explains the positive relationship between income and money demand. With regard to the third motive, it can be inferred that there is a negative relationship between money demand and interest rate. Furthermore, when people choose to hold money for speculative purposes, through investing in bonds or other forms of financial securities, they may tend to follow this behavior when interest rates are high; however, with lower interest rates, people may choose to hold money in cash rather than financial assets, since the opportunity cost of holding money is lower.

With this backdrop borne in mind, according to this theory, real money demand $\left(M_{t}^{d}\right)$ is determined by income and the interest rate. It is important to keep in mind that the money market reaches equilibrium when money demand $\left(M_{t}^{d}\right)$ equals money supply $\left(M_{t}^{s}\right)$. Put in different way, the money market condition for equilibrium can be written as follows:

$$
M_{t}^{d}=M_{t}^{s}
$$
follows:

Based on the identified determinants of real money demand, the money demand function can be written as

$$
M_{t}^{d}=\frac{M}{p}=f(Y, i)
$$

where $\left(\frac{M}{p}\right), M, P, Y, i$ denote the real money balance, broad money supply, price level, income and interest rate, respectively.

By expressing Equation 2 in a natural logarithm form (with the exception of the interest rate), it can be specified as follows:

$$
\ln \left(M_{t}^{d}\right)=\beta_{0}+\beta_{1} \ln \left(Y_{t}\right)+\beta_{2} i_{t}+e_{t}
$$

\footnotetext{
For instance, the end-of-1980 money supply figure used in our calculations for this paper is the weighted average of the monthly figures for Muharram and Safar 1401, corresponding to the December 7, 1980 to January 6, 1981 period. Common sense would tell us that this figure would be closer to the December 31, 1980 actual number than would the reported M3 figure for the end of Hijra fiscal 1400/1401, on May 4, 1981.

${ }^{2}$ It should be noted that the other data series used in the analysis were either always published on the Gregorian basis (CPI and interest rates), or were converted by GASTAT using similar methodology applied to annual data (GDP).
} 
where $e_{t}$ denotes the error term and $\beta_{0}, \beta_{1}$, and $\beta_{2}$ correspond to the estimated coefficients. It is noteworthy that $\beta_{1}$ and $\beta_{2}$ are expected to be positive and negative, respectively, in accordance with Keynesian theory.

\section{Literature Review}

An exploration of empirical work on money demand reveals the presence of tremendous research that has been conducted across several advanced and less advanced countries. Banafea (2012) covers an intensive literature review related to the demand for money from both theoretical and empirical perspectives. However, even with this large body of literature covering the demand for money and its determinants as well as relative issues, the literature highlights only a small number of studies analyzing the demand for money in Saudi Arabia. The prevailing literature concentrating on Saudi Arabia can be divided into two groups. Whereas the first group of studies relies on time series techniques, the second adopts panel data techniques, in which Saudi Arabia is included with other countries.

An overview of the research estimating the demand for money with the reliance on various econometric procedures enables us to identify the drawbacks of existing studies and how our study contributes to the standing studies. Beginning with the studies applying econometric time series methods, Alkaswani and AlTowaijari (1999) is one of the key studies that tried to understand the relation of money demand with its key determinants over both long and short runs with the utilization of annual data spanning over 1977-1997. Their empirical findings suggest the presence of a stable long run money demand function in Saudi Arabia. Specifically, the authors find evidence showing the significant and negative impact of interest and inflation rates on the demand for money over the long run, on one hand, and the positive and significant impact of output and real exchange rate on the demand for money, on the other. They also find that $35 \%$ of the demand for money tends to return to its steady state condition.

By employing an Autoregressive Distributed Lag (ARDL) model, Bahmani (2008) investigates the role of macroeconomic factors determining the demand for money in 14 Middle-Eastern economies including Saudi Arabia, using annual data from 1970-2004. Broadly speaking, the author's estimated models suggest the stability of the money demand function in most economies. The empirical results relevant to Saudi Arabia point to the influential role of income and inflation over the long run; moreover, the results reveal that money demand gets adjusted by $38 \%$ per year when it deviates from the long-run equilibrium. Similarly, Abdulkheir (2013) uses annual observations covering the 1987-2009 period to estimate the demand for money in Saudi Arabia. The author documents evidence indicating the important role of income, exchange rate, inflation, and interest rate in the determination of money demand in Saudi Arabia over the long run. Furthermore, when money demand deviates from its steady state condition, it needs about a year and nine months to return to its equilibrium level.

Other studies such as Banafea. (2014) and Al Rasasi (2016); Al Rasasi., Rawah, and Alghamdi (2020) put much emphasis on examining the stability of the money demand function. Banafea. (2014) estimates the demand for money over the 1980-2012 period and concludes that there is instability in the money demand in Saudi Arabia over that interval. Additionally, the parameters' estimates indicate the significant and positive impact of income on money demand, as well as the negative and significant impact of the interest rate on money demand over the long run. Conversely, Al Rasasi (2016) re-estimates the demand for money using quarterly data over the time horizon 1993:Q1 to 2015:Q3 and reaches a conclusion indicating the stability of money demand in Saudi Arabia. Additionally, the author documents that income affects the demand positively and significantly over the long run, while the interest and exchange rates affects the demand for money negatively; however, it is only the interest rate that has a significant impact. What is more, when the money demand moves away from its steady state condition, it takes the money demand about 1.4 percent each quarter to adjust to its steady state condition.

Hassanov, AL Rasasi, Al Sayaary, and Al-Fawzan (2017) examine the demand for money over the long run using annual data from 1987 to 2016 . The estimated money demand function confirms the stability of the long-run relationship between money demand and its key determinants. In most recent study, Al Rasasi and Banafea (2018) estimate the cash in advance model to capture the demand for money in Saudi Arabia employing quarterly data spanning over 2000-2016. Their empirical findings show the existence of stable long- and short-run relationships between money demand and its key determinants. Al Rasasi. et al. (2020) embed the money demand function with stock prices to assess their role in explaining the behavior of money in Saudi Arabia. The frequency of the data they utilize is quarterly and spanning from 2010 to 2018. Their empirical findings based on cointegration and error correction model indicate that the positive and influential impact of stock prices in capture the movements of money demand over long run; the authors also report that it takes money demand about two quarters to return back to its long run position.

Another strand of research (e.g. (Hamdi, Said, \& Sbia, 2015; Harb, 2004; Lee, Chang, \& Chen, 2008)) analyzes the money demand for the Gulf Cooperation Council (GCC) countries consisting of Bahrain, Kuwait, Oman, Qatar, Saudi Arabia, and the United Arab Emirates. Despite the different econometric panel data procedures, the findings of these studies confirm the presence of a stable relationship among money demand and its determinants over the long run. 
An overview of the existing studies analyzing the demand for money in Saudi Arabia reveals some deficiencies. First, none of the existing studies that analyze the demand for money in Saudi Arabia going back to the 1970 s and the early 1980 s treats the issue of converting the money supply data from the Hijra to the Gregorian calendar, as introduced by Qualls et al. (2017). ${ }^{3}$ Furthermore, some of the studies relied solely on the US interest rate rather than Saudi rate due to the lack of data. What is more, existing studies tend to use money supply measures based on the end of the period, usually a year. Additionally, most recent studies (e.g. Al Rasasi and Banafea (2018)) that analyzed the demand for money in Saudi Arabia do not treat the issue of the new base year and data revisions for the consumer price index. Based on the aforementioned identified issues, therefore, we aim in this paper to enrich the existing empirical literature by dealing with the issue of pre-1988 data, on one hand, and comparing the estimates of money demand function by using monthly average money supply data versus end of year, on the other hand.

\section{Data}

Annual data spanning from 1980 to 2017 are used to estimate the demand for money in Saudi Arabia. The dataset consists of the end-of-year broad money supply (M3), the average broad money supply (M3) calculated by averaging monthly data, the consumer price index (CPI) with the 2013 base year, real private sector activities GDP as a measure of income, and the 3-month Saudi Arabian Interbank Offered Rate (SAIBOR). It is important to note that due to the unavailability of SAIBOR data prior to 1984, we use the 3-month London Interbank Offered Rate (LIBOR) as a proxy. ${ }^{4}$ All data items are extracted from various sources; monetary data are obtained from the SAMA databases (converted, where necessary, from the Hijra to the Gregorian calendar, as described earlier in this paper), while real private sector activity GDP and CPI are downloaded from the General Authority for Statistics (GASTAT). CPI data prior to 2001 are derived by linking the previous series (with a 2007 base year) to the new 2013 data. The data for the LIBOR interest rate used in the 1980-1983 period are obtained from the Oxford Economics database. We express all variables with the exception of the interest rate in natural logarithm form.

\section{Empirical Methodology \\ 5.1. Preliminary Investigation}

It has become a standard procedure in macroeconomic analysis to evaluate the stochastic properties of macroeconomic time series in order to avoid false interpretation of the estimated results, in particular, the problem of spurious relationship. For this purpose, eminent economists (e.g. (Dickey \& Fuller, 1979; Phillips \& Perron, 1988)) have developed various unit root tests evaluating the time series properties to avoid falsely results. Therefore, it is important to check the stochastic properties of the utilized macroeconomic variables in this paper. To do so, we applied the unit root tests originated by Kwiatkowski, Phillips, Schmidt, and Shin (1992) and Elliot, Rothenberg, and Stock (1996)since they are more efficient and can overcome the issues with earlier unit root tests. In other words, unit root tests such as Dickey and Fuller (1979) and Phillips and Perron (1988) seem to be weak in power as noted by Schwert (1987). The obtained results of these tests are summarized in Table 1 and confirm that all variables are integrated of order one.

Table-1. Kwiatkowski et al. (1992) \& Elliot et al. (1996) Unit Root Tests

\begin{tabular}{l|c|c|c|c|c|c|c|c}
\hline & \multicolumn{4}{|c}{ KPSS Test } & \multicolumn{3}{c}{ ERS Test } \\
\hline & \multicolumn{2}{|c|}{ Level Data } & \multicolumn{2}{c|}{ First Difference } & \multicolumn{2}{c}{ Level Data } & \multicolumn{2}{c}{ First Difference } \\
\hline & Constant & Trend & Constant & Trend & Constant & Trend & Constant & Trend \\
\hline GDP & 0.93 & 0.25 & 0.42 & 0.11 & -1.22 & -1.77 & -2.33 & -2.51 \\
\hline MD3-end & 1.03 & 0.17 & 0.13 & 0.13 & -0.34 & -2.12 & 0.07 & -1.04 \\
\hline MD3-avg & 1.03 & 0.17 & 0.14 & 0.13 & 0.26 & -2.39 & -0.29 & -1.16 \\
\hline Interest & 0.91 & 0.12 & 0.05 & 0.14 & -0.11 & -1.87 & -1.69 & -2.82 \\
\hline
\end{tabular}

Note:

The KPSS $5 \%$ critical values for constant $=0.463$, and for trend $=0.146$. for the Elliott et al. constant $=-1.94$, and for trend $=-3.03$.

The null hypothesis of KPSS test is that the variable is stationary against the alternative stating the variable is not stationary.

Regarding the ERS test, the null hypothesis states that the variable is non-stationary against the alternative stating the variable is stationary.

Finding the variables being integrated of order one suggests that there might be a cointegration relationship among these variables, as pointed out by Engle and Granger (1987). This in turn motivates us to apply the most popular cointegration tests initiated by Johansen and Juselius (1990) in order to assess whether there are multiple cointegration relationships or not. This is very important especially with the use of new Gregorian money supply data. The results of all tests as presented in Tables 2 and 3 confirm the presence of at least two cointegration relationships. In other words, there exists a cointegration relationship among the real balance of money demand, income measured by the real private sector activities GDP, and interest rate. This

${ }^{3}$ The GDP data prior to 1988 were converted to the Gregorian calendar by GASTAT in the 2002-2003 period; thus, all studies done prior to that date were forced to use Hijra data for periods earlier than 1986.

${ }^{4}$ Admittedly, the Saudi riyal was not tightly pegged to the US dollar prior to mid-1986, but the large dollar-denominated capital inflows during this period, the primacy of dollar-denominated oil revenues in Saudi exports, and the lack of a suitable alternative led to this substitution in the $1980-83$ period. 
finding indicates that all variables tend to move together over time implying that the estimated relationship using the variables in levels is not spurious. Therefore, the estimated coefficients of the cointegration relationship are valid for analysis and forecasting.

Table-2. Johansen and Juselius (1990) Cointegration Test. End of Period Money Supply (M3)

\begin{tabular}{c|c|c|c}
\hline Null Hypothesis & Alternative Hypothesis & Test Statistics & 5\% Critical Value \\
\hline \multicolumn{4}{c}{ Panel A: Trace Test } \\
\hline$r=0$ & $r=1$ & 56.60 & 34.91 \\
\hline$r \leq 1$ & $r=2$ & 22.74 & 19.96 \\
\hline$r \leq 2$ & $r=3$ & 8.30 & 9.24 \\
\hline$r=0$ & $r=1$ & 33.86 & 22.00 \\
\hline$r \leq 1$ & $r=2$ & 14.44 & 15.67 \\
\hline$r \leq 2$ & $r=3$ & 8.30 & 9.24 \\
\hline \multicolumn{4}{r|}{ Panel B: Maximum Eigenvalue Test } \\
\hline
\end{tabular}

Table-3. Johansen and Juselius (1990) Cointegration Test.

\begin{tabular}{c|c|c|c}
\hline \multicolumn{5}{c}{ Averaged Monthly Money Supply (M3) } \\
\hline Null Hypothesis & Alternative Hypothesis & Test Statistics & 5\% Critical Value \\
\hline \multicolumn{4}{c}{ Panel A: Trace Test } \\
\hline$r \leq 1$ & $r=1$ & 54.44 & 34.91 \\
\hline$r \leq 2$ & $r=2$ & 20.88 & 19.96 \\
\hline$r=0$ & $r=3$ & 6.03 & 9.24 \\
\hline$r \leq 1$ & Panel B: Maximum Eigenvalue Test & 22.00 \\
\hline$r \leq 2$ & $r=1$ & 33.56 & 15.67 \\
\hline
\end{tabular}

Note: $r$ denotes the number of cointegration vectors.

\subsection{Estimation of the ECM Model Using the Generalized One-Step Procedure}

Once the existence of the cointegration relationship has been confirmed, we can proceed with the estimation step in order to interpret the long and short run relationships. To do so, we have chosen the generalized one-step procedure ${ }^{5}$, which combines both the short-term (delta logged form) and long-term (logged form) into a single equation, as specified in Equation 4.

$$
\begin{aligned}
& \Delta \ln \left(M_{t}^{d}\right)=\beta_{0}+\beta_{1} \Delta \ln \left(M_{t-1}^{d}\right)+\beta_{2} \Delta \ln \left(Y_{t}\right)+\beta_{3} \Delta i_{t}+\lambda *\left[\ln \left(M_{t-1}^{d}\right)-\left\{\left(\frac{\beta_{4}}{\lambda}\right) \ln \left(Y_{t-1}\right)+\right.\right. \\
& \left.\left.\left.\left(\frac{\beta_{5}}{\lambda}\right) i_{t-1}\right)\right\}\right]+\beta_{6} D_{1}+\beta_{7} D_{2}+e_{t}
\end{aligned}
$$

where $\Delta$ denotes the change, while $\ln \left(M_{t}^{d}\right), \Delta \ln \left(Y_{t}\right), i_{t}$ are the logarithm of money demand, the logarithm of GDP, and the Saudi interest rate, respectively. In the same vein, $\boldsymbol{\lambda}$ can be interpreted as the speed of adjustment to the steady state condition, since it is applied to the error term which is contained within the square brackets. As such, it should be negative, with a value between 0 and -1 . The first term within the brackets is the log of the actual lagged dependent variable. The second and third terms (between the parentheses) are the calculated value of the lagged dependent variable. The second term is the log of the first independent variable (GDP) - thus, $\beta_{4} / \lambda$ can be interpreted as the long-term income elasticity. The third term, $\beta_{5}$, is the long-term effect of the interest rate and should be negative - i.e., higher interest rates should be associated with lower levels and growth of money demand.

It is important to highlight that $D_{1}$ and $D_{2}$ are dummy variables, in which $D_{1}$ takes the value of unity (1) during the years of 1980-83 and zero after 1984. Likewise, the dummy variable $D_{2}$ takes the value of unity in 1984 and zero otherwise. These variables were added in order to see if the use of the LIBOR proxy for Saudi interest rates causes a significant distortion in the estimated model. The 1980-83 dummy covers the long-

\footnotetext{
${ }^{5}$ According to De Boef (2001) this procedure is better than the two-step procedure not only because it is theoretically appealing, but also statistically superior. It is important to bear in mind that "the generalized one-step procedure is a transformation of an autoregressive lag "ADL" model as indicated by Banerjee, Dolado, Galbraith, and Hendry (1993)" who showed that the estimated dynamic models "will be asymptotically equivalent to more complex full-information maximum-likelihood and fully modified estimators when the processes are weakly exogenous." This in turn means that the estimated coefficient from the onestep procedure will be not only unbiased, but also efficient and consistent.
} 
term, log-linear portion of the equation, while the 1984 dummy is for the short-term delta log (growth rate) portion.

Table-4. Parameter estimates of the ECM.

\begin{tabular}{c|c|c|c|c|c|c|c|c|c|c}
\hline & \multicolumn{10}{|c}{ End-of-Period Money Supply (M3) } \\
\hline & $\beta_{0}$ & $\beta_{1}$ & $\beta_{2}$ & $\beta_{3}$ & $\beta_{4}$ & $\beta_{5}$ & $\lambda$ & $\beta_{6}$ & $\beta_{7}$ & Adj R $^{2}$ \\
\hline Estimates & -0.59 & 0.29 & 1.07 & -0.008 & 0.29 & -0.0007 & -0.24 & -0.19 & -0.04 & 0.3793 \\
\hline S.E. & 0.39 & 0.16 & 0.29 & 0.006 & 0.12 & 0.0057 & 0.10 & 0.07 & 0.06 & S.E. Regression \\
\hline$T$-values & -1.52 & 1.83 & 3.67 & -1.267 & 2.39 & -0.1237 & -2.37 & -2.76 & -0.73 & 0.039056 \\
\hline
\end{tabular}

The estimated results of Equation 4 are shown in Table 4. Based on the reported results, the long-term elasticity for GDP is the regression coefficient's estimate of the lagged log GDP term $\left(\boldsymbol{\beta}_{4}=0.292519\right)$ divided by the absolute value of the coefficient on the lagged log M3 term $(\lambda=0.242732)$, so the long-term elasticity for GDP is $\left(\frac{\beta_{4}}{|\bar{\lambda}|}=1.205\right)$. This is slightly higher than the value of the coefficient on $\beta_{2}(1.07)$, which is the short-term income elasticity of demand. The long-term coefficient for the interest rate is calculated in the same way; thus, the coefficient is $\left(\frac{\beta_{5}}{|\lambda|}=-0.0029\right)$.

The coefficient on the lagged $\log$ M3 term is referred to as $\lambda$, and its estimated value must be between -1 and $\mathrm{o}$ and is interpreted in absolute value. This parameter is also known as the speed of adjustment, or the percent of the last period's long-term error (deviation from equilibrium) that needs to be applied to the current period's short-term growth. In this case, the speed of adjustment is 24.3 percent; in other words, when money demand deviates from its equilibrium due to unexpected shocks, 24.3 percent of the deviation will be corrected to the steady state level within one year implying that the full correction to the steady state condition will take more than three years. However, we should not make too much of this relatively slow rate of long-term convergence, since the short-term elasticity is nearly as large (1.07), indicating that most of the adjustment takes place in the same year as the change in GDP.

The coefficient on the lagged dependent variable $\left(\beta_{1}=0.293\right)$ is fairly high; however, it is not statistically significant. This is understandable, given that these are annual data, and one would expect that the contemporaneous independent variables (GDP and the interest rate) would exert considerably more influence than would last year's M3 growth. The values of the GDP elasticities (1.07 in the short-run and 1.21 in the long-term) are in general agreement with theory-based expectations, since both are greater than the unity and the long-run elasticity is higher than the short-run value. In addition, the $t$-statistics (both greater than 2) indicate that this relationship is robust.

However, even though the coefficients on both the short and long-term interest rates are negative (as theory would predict), they are very small and the $t$-statistics are very low, particularly for the long-term coefficient. This might be explained by the fact that interest rates for the last 10 years have been very low, accompanied by a slowdown in real non-oil private activity growth in the last several years. Also, we might add that the Saudi economy is not known as being sensitive to interest rates as are the developed nations, and the weak $t$-statistics reflect this hypothesis. Unfortunately, all we can say for sure is that neither the short nor the long-term interest rate coefficients are significantly different from zero.

Furthermore, note that the coefficient $\left(\beta_{6}\right)$ of the dummy variable "D 1" is significant, indicating that there may be problems with using the US 3 month LIBOR as a proxy for SAIBOR. In addition, the 1980-83 period was a turbulent economic period, marked by a substantial decline in oil prices and volumes in the latter two years of the interval.

In a similar manner, Table 5 shows the results of fitting the generalized single step ECM model, using the M3 average value for the dependent variable.

Table-5. Parameter estimates of the ECM.

\begin{tabular}{c|c|c|c|c|c|c|c|c|c|c|c}
\hline & \multicolumn{10}{c}{ Average Money Supply (M3) } \\
\hline & $\beta_{0}$ & $\beta_{1}$ & $\beta_{2}$ & $\beta_{3}$ & $\beta_{4}$ & $\beta_{5}$ & $\lambda$ & $\beta_{6}$ & $\beta_{7}$ & $\mathrm{Adj}^{2}$ \\
\hline Estimates & -0.54 & 0.36 & 0.92 & -0.008 & 0.28 & -0.0019 & -0.23 & -0.15 & -0.04 & 0.585896 \\
\hline S.E & 0.30 & 0.14 & 0.21 & 0.005 & 0.10 & 0.0046 & 0.08 & 0.06 & 0.05 & S.E. Regression \\
\hline$T$-values & -1.79 & 2.55 & 4.37 & -1.629 & 2.91 & -0.405 & -2.87 & -2.74 & -0.99 & 0.031619 \\
\hline
\end{tabular}

Applying the same way as in Table 4, we obtain the long-term elasticity of GDP $\left(\frac{\beta_{4}}{|\lambda|}=1.198\right)$ and the coefficient for the interest rate is $\left(\frac{\beta_{5}}{|\lambda|}=-0.00810\right)$. As was the case for the Table 4 equation, the $t$ - 
statistics on both the short and long-term interest rate coefficients are less than 2 in absolute value, indicating that the coefficients are not significantly different from zero. However, this equation is much more robust than that in Table 4. The lagged dependent variable $\Delta \ln \left(M_{t-1}^{d}\right)$, with a value of 0.363 , is significant at the $95 \%$ level, the $t$-statistics are higher for all of the variables in the model, the adjusted R-squared value (the percent of variance explained by the model), is 58.6 percent, versus 37.9 percent in the M3 end-of-period model, and the standard error of the regression is 3.2 percent versus 3.9 percent in the other model. This is strong evidence that the use of the monthly average of M3 produces a superior estimation of the relationship between M3 and its determinants than does the end-of-month method.

\section{Conclusion}

The main objective of this paper is not to conduct a classic study of the demand for money in Saudi Arabia. As it can be seen from the literature review, this issue has been extensively studied. Rather, we aimed at exploring two questions that are interrelated and data-driven. The first question is related to the historical monthly and annual Hijra data that are present in many of the series published in previous annual reports by SAMA. There can be no question on this issue since these data are not accurate representations of the actual activities on the Gregorian dates that are assumed to be correct by their users. Any attempt to use these historical data in sophisticated econometric models that use time-dependent tools (e.g., autoregressive lagged dependent variables, vector autoregression, error correction modeling, etc.,) suffer from spurious estimations. Even a simple compound annual growth rate calculation can be misleading, given the 354-355 day length of the Hijra year. The conversion methodology used for the M3 data in this paper is only an approximation of what the data would have actually been using a Gregorian calendar, but, in our opinion, it is a far better way of handling the problem than continuing to use the Hijra data as published.

The second question we addressed is the seeming mismatch of the statistical data typically used in the simple money demand equations. This, in turn, suggests the need for the used data to be consistent with no mismatch to ensure the accuracy of the estimated results. Thus, the use of end-of-period data for items such as the money supply, bank lending, and other financial balance sheet items, and attempting to relate these data to variables that are expressed as averages or sums (e.g., income, price levels, and interest rates) would seem to be inconsistent. It also causes serious problems when combined with the Hijra data problem mentioned above.

The results of our analysis strongly suggest that the converted Hijra data are capable of giving robust results when used in typical econometric analyses, with no signs of instability in the short or long runs. In addition, they suggest that the use of monthly average data for the money stock improves the stability and goodness-of-fit of both the short and long-run ECM specifications. We are not recommending that statistical agencies using the Hijra calendar stop publishing their data in the traditional format, but consideration should be given to using these revised statistics in future research in this area. At the very least, the agencies should notify users that the Hijra dates are for a year that is three percent shorter than the Gregorian year, and that stock data which depends on ending period values are for a date that differs greatly from the December 31 ending period for Gregorian-based data.

\section{References}

Abdulkheir, A. Y. (2013). An analytical study of the demand for money in Saudi Arabia. International Journal of Economics and Finance, 5(4), 31-38.

Al Rasasi, M. (2016). On the stability of money demand in Saudi Arabia. SAMA Working Paper, No. 6/2016.

Al Rasasi, M., \& Banafea, W. (2018). Estimating money demand function in Saudi Arabia: Evidence from cash in advance model. SAMA Working Paper, No. 4/2018.

Al Rasasi., M., Rawah, F., \& Alghamdi, B. (2020). On the nexus between stock market fluctuations and the demand for money in Saudi Arabia. Business and Economic Research, 10(1), 142-154.

Alkaswani, M., \& Al-Towaijari, H. (1999). Cointegration, error correction and the demand for money in Saudi Arabia. Economia Internazionale/ International Economics, 52(3), 299-308.

Bahmani, S. (2008). Stability of the demand for money in the middle East. Emerging Markets Finance and Trade, 44(1), 6283.Available at: https://doi.org/10.2753/ree1540-496x440104.

Banafea, W. A. (2012). Essays on structural breaks and stability of the money demand function. PhD Thesis, Kansas State University.

Banafea., W. A. (2014). Endogenous structural breaks and the stability of the money demand function in Saudi Arabia. International Journal of Economics and Finance, 6(1), 155-164.Available at: https://doi.org/10.5539/ijef.v6n 1p155.

Banerjee, A., Dolado, J. J., Galbraith, J. W., \& Hendry, D. (1993). Co-integration, error correction, and the econometric analysis of non-stationary data. Oxford: Oxford University Press.

De Boef, S. (2001). Modeling equilibrium relationships: Error correction models with strongly autoregressive data. Political Analysis, 9(1), 78-94.

Dickey, D. A., \& Fuller, W. A. (1979). Distribution of the estimators for autoregressive time series with a unit root. Journal of the American statistical association, 74(366a), 427-431.Available at: https://doi.org/10.2307/2286348.

Elliot, G., Rothenberg, T. J., \& Stock, J. H. (1996). Efficient tests for an autoregressive unit root. Econometrica, 64(4), 813836.

Engle, R. F., \& Granger, C. W. (1987). Co-integration and error correction: representation, estimation, and testing. Econometrica: Journal of the Econometric Society, 55(2), 251-276. 
Hamdi, H., Said, A., \& Sbia, R. (2015). Empirical evidence on the long-run money demand function in the Gulf Cooperation Council countries. International Journal of Economics and Financial Issues, 5(2), 603-612.

Harb, N. (2004). Money demand function: A heterogeneous panel application. Applied Economics Letters, 11(9), 55 1-555.

Hassanov, F. J., AL Rasasi, M. H., Al Sayaary, S., \& Al-Fawzan, Z. (2017). Demand for broad money in Saudi Arabian economy. SAMA Working Paper, No. 6/2017.

Johansen, S., \& Juselius, K. (1990). Maximum likelihood estimation and inference on cointegration-with appucations to the demand for money. Oxford Bulletin of Economics and statistics, 52(2), 169-210.Available at: https://doi.org/10.1111/j.1468-0084.1990.mp52002003.x.

Kwiatkowski, D., Phillips, P. C., Schmidt, P., \& Shin, Y. (1992). Testing the null hypothesis of stationarity against the alternative of a unit root. Journal of Econometrics, 54(1-3), 159-178.

Lee, C.-C., Chang, C.-P., \& Chen, P.-F. (2008). Money demand function versus monetary integration: Revisiting panel cointegration among GCC countries. Mathematics and Computers in Simulation, 79(1), 85-93.Available at: https://doi.org/10.1016/j.matcom.2007.10.003

Phillips, P. C., \& Perron, P. (1988). Testing for a unit root in time series regression. Biometrika, 75(2), 335-346.Available at: https://doi.org/10.1093/biomet/75.2.335.

Qualls, J. H., Algahtani, G. J., \& Al Sayaary, S. (2017). Note on the conversion of annual and monthly data from the Hijra to the Gregorian calendar. SAMA Working Paper, No. 17/7.

Schwert, G. W. (1987). Effects of model specification on tests for unit roots in macroeconomic data. Journal of Monetary Economics, 20(1), 73-103.Available at: https://doi.org/10.1016/0304-3932(87)90059-6. 